\title{
Estaquia de rizomas do carapiá, planta medicinal em extinção
}

\author{
José Magno Q Luz; André F Carvalho; Michele C de Oliveira \\ UFU-ICIAG, C. Postal 593, 38400-902 Uberlândia-MG; jmagno@umuarama.ufu.br; andrefcarvalho@yahoo.com.br; michele_agro@ \\ yahoo.com.br
}

\section{RESUMO}

Dorstenia cayapia Vellozo, Moraceae (carapiá) é uma erva medicinal e nativa do Brasil. Pertence à categoria "vulnerável", devido à drástica redução dos seus habitats e ao declínio populacional. Esta pesquisa foi realizada em casa de vegetação pertencente ao Centro de Ciências Agrárias da Universidade Federal de Uberlândia. Teve como objetivo obter informações agronômicas que permitam cultivar e explorar racionalmente o carapiá, visando a obtenção de material cultivado para produtos fitoterápicos e indústria química. $\mathrm{O}$ material vegetal foi coletado em Raul Soares-MG, em um resquício de Floresta da Encosta Atlântica. Nesse experimento de estaquia de rizomas avaliaram-se três substratos: Substrato comercial, S1 (40\% terra $+40 \%$ esterco bovino $+20 \%$ húmus $)$ e S2 $(20 \%$ terra $+20 \%$ esterco bovino $+40 \%$ húmus $+20 \%$ vermiculita); três partes de rizoma: apical, basal e mediano e dois tipos de bandeja de poliestireno expandido com 128 e 200 células. Adotaram-se estacas com o tamanho médio de $2 \mathrm{~cm}$, que foram plantadas de acordo com o geotropismo positivo. Conduziu-se o experimento de abril a junho de 2007. O delineamento foi inteiramente casualisado em esquema fatorial (3x3x2). Determinou-se a brotação (\%) aos 30 e 68 dias após o plantio (DAP) e as massas fresca e seca da parte aérea (folhas e inflorescências) e da parte subterrânea (rizomas e raiz) aos 68 DAP. Os substratos não tiveram efeito na brotação dos rizomas em bandejas aos 30 DAP. A brotação da parte apical do rizoma foi superior às brotações das posições basal e mediana do rizoma aos 68 DAP. Comparando o uso das bandejas de 128 e de 200 células, a brotação dos rizomas foi superior com o uso da bandeja de 128 células. Pode-se recomendar, para o plantio de Dorstenia cayapia, o corte da parte apical do rizoma, evitando-se assim, o arranquio da planta inteira, auxiliando na preservação dos indivíduos em seu ambiente natural e possibilitando sua propagação assexuada.

Palavras-chave: Dorstenia cayapia Vellozo, brotação, substratos, conservação, propagação assexuada.

\section{ABSTRACT \\ Rhizome cuttings of Carapiá, a medicinal plant vulnerable to extinction}

Dorstenia cayapia Vellozo, Moraceae (carapiá) is a Brazilian native medicinal herb that is classified as "vulnerable" because of the drastic reduction of its habitat and its declining population. This study was carried out in a greenhouse at the Center for Agricultural Sciences, Federal University of Uberlândia, Minas Gerais State, Brazil. The objective of the study was to obtain informations about cultivation and exploration of carapiá to obtain plant material for phytotherapy and chemical industry products. Plant material was collected in Raul Soares, Minas Gerais State, in a fragment of the Atlantic Coastal Forest. Three substrates were evaluated in the rhizome cutting experiment: Commercial substrate, S1 (40\% soil + $40 \%$ cattle manure $+20 \%$ humus $)$; S $2(20 \%$ soil $+20 \%$ cattle manure $+40 \%$ humus $+20 \%$ vermiculite); three sections of the rhizome: apical, basal and intermediate and two types of trays: 128 and 200 cells. Medium sized cuttings $(2 \mathrm{~cm})$ were prepared and planting was done according to positive geotropism. The experiment was carried out from April to June 2007 and the experimental design was completely randomized as a $3 \times 3 \times 2$ factorial. Dry mass was determined for the above ground (leaves and inflorescences) and for the under ground (roots and rhizomes) parts of the plant. The rhizome tip sprouting was greater than those of the median and basal sections. Rhizome sprouting was better in the 128-cells tray than in the 200cell tray. Collecting cuttings from the top of the rhizomes could be recommended for planting because it avoids removing the entire plant, thus preserving the plants in their environment and providing for the possibility of asexual propagation.

Keywords: Dorstenia cayapia Vellozo, sprouting, substrates, conservation, asexual propagation.

\section{(Recebido para publicação em 26 de agosto de 2010; aceito em 10 de maio de 2011)}

(Received on August 26, 2010; accepted on May 10, 2011)

$\mathrm{O}$ gênero Dorstenia (carapiás) é, talvez, sob o ponto de vista químico, o mais importante da Família Moraceae, juntamente com o gênero Cecropia (embaúbas) e Ficus (figueiras), devido à presença de furocumarinas, princípio ativo correlacionado a diversas funções (comunicação pessoal, Pedro Carauta ${ }^{1}$, 2007). Os carapiás constam na Lista Vermelha das espécies ameaçadas de extinção da flora de Minas Gerais (Mendonça \& Lins, 2000), sendo mencionadas as espécies: Dorstenia arifolia (vulnerável), D. cayapia (vulnerável), D. elata (vulnerável) e $D$. sucrei (criticamente em perigo). Além do uso medicinal, as dorstênias apresentam grande potencial como plantas ornamentais, principalmente em locais de pouco sol direto.

$\mathrm{O}$ ambiente à sombra de árvores, onde a maioria das dorstênias habita, torna os carapiás sensíveis à degradação ambiental, pois uma vez destruída a floresta, determina-se condição desfavo- rável à sobrevivência desses indivíduos, muito sensíveis à variação de luminosidade. Outro problema que os carapiás sofrem é o extrativismo predatório, para fins medicinais, pois as partes mais utilizadas, como fonte de princípios ativos, são os rizomas, visto que, para serem extraídos, arranca-se a planta inteira. Os rizomas são vendidos a ervanários ou grandes laboratórios, que comercializam produtos nos quais entram como composição única ou de forma composta. Esta

${ }^{1}$ Pesquisador do Museu Nacional, Depto. Botânica, Rio de Janeiro-RJ 
situação é comum no Mercado Central de Belo Horizonte-MG.

O gênero Dorstenia possui nos rizomas furocumarinas (psoraleno, bergapteno, prenilfurocumarina, ácido p-cumárico), terpenos, óleos essenciais, ácido dorstênico e ácidos graxos. Os seguintes usos etnofarmacológicos foram identificados para o carapiá: eupética, tônica digestiva, afecções da pele, antiespasmódica, emenagoga, febrífuga, antidiarréica, diurética e para consolidação de fraturas (Botsaris \& Machado, 1999).

Dorstenia cayapia Vellozo é conhecida pelos nomes populares de caiapiá-verdadeiro e carapiá. Erva umbrófila ou semi-umbrófila, crescendo em solo arenoso, resiste mais ao ambiente seco do que à umidade excessiva. Quando o ambiente é seco o caule aéreo é nulo, aparecendo apenas as folhas, surgidas diretamente do solo. Os rizomas têm entrenós curtíssimos, de látex branco-leitoso. A lâmina foliar é geralmente cordiforme ou deltóide, e na face superior, em geral, apresenta duas grandes manchas verde-claras. $\mathrm{O}$ cenanto (receptáculo carnoso onde se alojam as sementes) tem contorno circular, violáceo; os femininos são robustos e os masculinos delgados. Em condições ecológicas favoráveis as dorstênias florescem e frutificam durante todo o ano. Quando os frutos amadurecem, as sementes são projetadas à distância, de modo brusco, com um pequenino estalo (Carauta, 1978).

$\mathrm{Na}$ condução deste trabalho (ambiente seco)observou-se que a planta aparecia com as folhas surgidas diretamente do solo, como caracterizado por Carauta (1978). O carapiá é uma espécie da flora brasileira, ocorrendo nos estados do Mato Grosso, Goiás, Minas Gerais, Rio de Janeiro, São Paulo e Paraná. (Carauta, 1978).

São numerosos os trabalhos científicos publicados sobre a composição química e ação medicinal do carapiá, nos seres humanos: alguns trabalhos de etnobotânica; apenas um de micropropagação, com uma espécie africana (Dorstenia gigas) (Krogstrup et al., 2005) e nenhum de propagação dos carapiás brasileiros. Portanto, faltam pesquisas sobre a sua propagação e o posterior cultivo, o que auxiliaria muito na preservação da espécie e da fonte de material cultivado e não retirado da natureza, para produtos fitoterápicos.

$O$ interesse da pesquisa na propagação de plantas medicinais é bastante recente e tem-se concentrado na verificação dos melhores tipos e comprimentos de estaca, no efeito do uso de reguladores de crescimento e nos substratos mais adequados para o enraizamento (Costa et al., 2007).

Diante do exposto, este trabalho teve como objetivo obter informações agronômicas que permitam cultivar e explorar racionalmente o carapiá, visando a sua propagação por meio de estacas de rizomas.

\section{MATERIAL E MÉTODOS}

O material vegetal foi coletado em 15 de abril de 2007, na Fazenda Oriente. Adotou-se essa fazenda, porque a planta havia sido anteriormente herborizada (coletor André Furtado Carvalho, número de coleta: 256 em 24 de novembro de 1992), mantida no Herbário da Biologia Vegetal da Universidade Federal de Viçosa, MG e identificada por Carauta, em fevereiro de 1994. Dessa forma, garantiu-se que o trabalho fosse realizado com a espécie mencionada.

A Fazenda Oriente está situada no município de Raul Soares, MG (2006'07”S; 42²7'10”'W; $294 \mathrm{~m}$ de altitude). A temperatura média máxima anual é de $27,6^{\circ} \mathrm{C}$ e a mínima de $15,4^{\circ} \mathrm{C}$, com precipitação média anual de $1.860,8 \mathrm{~mm}$. Segundo a classificação de Köppen (Setzer, 1946), o clima da região varia do tipo $\mathrm{Cwa}$, tropical úmido a Aw, semi-úmido de verões quentes.

Foram 384 plantas utilizadas para o experimento, encontrando-se, nesse material, 21 plantas com cenanto feminino, contendo sementes. As plantas coletadas foram levadas a Uberlândia, onde foram lavadas com água corrente (para retirar o excesso de terra e não eliminar algum possível microorganismo simbionte, como micorrizas), retirada a parte aérea (separando os cenantos com sementes). Como o rizoma de carapiá é vertical, os entrenós são curtíssimos (1 a 2 mm) e os rizomas das plantas coletadas raramente atingiram comprimento superior a $8 \mathrm{~cm}$; adotou-se estaca com o tamanho médio de $2 \mathrm{~cm}$, conseguindo-se, assim, as três partes do rizoma (apical, mediana e basal) de uma mesma planta contendo, em cada fração de rizoma, um número superior a dez gemas.

As frações de rizoma foram plantadas, respeitando a polaridade (geotropismo positivo), em 19 de abril de 2007, em bandejas de poliestireno expandido de 128 e 200 células (total de 24 bandejas), utilizando-se três substratos: Comercial; S1 $(40 \%$ solo $+40 \%$ esterco bovino + $20 \%$ húmus) e S2 $(20 \%$ solo $+20 \%$ esterco bovino $+40 \%$ húmus $+20 \%$ vermiculita).

As bandejas foram dispostas sobre bancada de cimento na casa de vegetação da Fitotecnia, Campus Umuarama. Cada bandeja recebeu apenas um tipo de substrato, e as três posições de rizoma. As bandejas de 128 e de 200 células, bem como a posição dos rizomas (apical, basal e mediano), dentro da bandeja, foram dispostos aleatoriamente. Ao total foram utilizadas 1.152 partes de rizoma.

O teste de brotação de rizomas de Dorstenia cayapia, em diferentes combinações de substrato (P, S1 e S2), bandeja (128 e 200 células) e posição do rizoma (apical, mediano e basal), foram analisados em delineamento inteiramente casualizado, em esquema fatorial de $2 \times 3 \times 3$ (bandeja $\times$ substrato $\times$ posição do rizoma), com quatro repetições de 16 rizomas cada.

Foi utilizada a irrigação por aspersão uma ou duas vezes por dia, dependendo da umidade do substrato. Avaliou-se o número e a porcentagem de brotação aos 30 dias. Aos 68 dias foram analisadas a porcentagem de brotação, a massa fresca e seca, em gramas (g), da parte aérea (folha + cenanto) e subterrânea (rizoma + raiz).

A avaliação da massa fresca e seca foi realizada com dez plantas de cada parcela. Todas as características foram inicialmente testadas quanto às pressuposições de normalidade dos resíduos (teste de Shapiro-Wilk) e homogeneidade entre variâncias (teste de Bartlett). Como para todas as características as pressuposições não foram atendidas, os dados foram transformados pela equação $\sqrt{x+0,5}$ e submetidos ao teste de 
Tukey a 0,05 de significância.

\section{RESULTADOS E DISCUSSÃO}

Verificou-se interação significativa entre as partes do rizoma (apical, mediana e basal) e bandejas (128 e 200 células) e, efeito significativo para o tipo de substrato utilizado aos 30 dias após o plantio dos rizomas (Tabela 1). Na bandeja de 128 células, com maior volume de substrato, houve maior brotamento dos rizomas apicais e os substratos não diferiram entre si, quanto à brotação geral dos rizomas.

Houve interação significativa aos 68 dias após o plantio dos rizomas entre o substrato e a bandeja e as partes do rizoma foram analisadas de forma isolada. (Tabela 2). Houve maior brotamento dos rizomas apicais, significativamente superior às outras partes do rizoma, independentemente do tipo de bandeja utilizada. Quanto ao substrato, o Comercial foi o que mais favoreceu as brotações para bandejas de 128 células, sem diferir estatisticamente da porcentagem de brotação de rizomas de carapiá no substrato S2. Para bandejas de 200 células, o tipo de substrato foi indiferente em relação a porcentagem de brotação.

A superioridade do rizoma apical, em relação à brotação, possivelmente se deve ao tecido meristemático ser menos lignificado do que o rizoma mediano e basal, supondo-se que o rizoma apical tenha mais reserva nutricional e que os pontos de crescimento estejam no ápice do rizoma. Lopes et al. (2003) concluíram que o desenvolvimento foliar das plantas, obtido em segmentos de rizomas não apicais, é bem mais lento do que em rizomas apicais, trabalhando com Limonium brasiliense. Essa informação permite, a quem queira cultivar Dorstenia cayapia por estaquia de rizoma, o corte apenas da parte apical, com $2 \mathrm{~cm}$, deixando o restante do rizoma no ambiente, fazendo assim um manejo sustentável.

Até 30 dias após o plantio, nenhum substrato favoreceu as brotações, porém aos 68 dias o Comercial foi o substrato que promoveu maior formação de brotos.

Quanto à brotação das gemas de

Tabela 1. Brotação de rizoma (\%) de Dorstenia cayapia aos 30 dias após o plantio (rhizome budding (\%) of Dorstenia cayapia 30 days after planting). Uberlândia, UFU, 2007.

\begin{tabular}{|c|c|c|c|c|}
\hline \multirow{2}{*}{ Rizoma } & \multicolumn{2}{|c|}{ Bandejas } & \multirow{2}{*}{\multicolumn{2}{|c|}{ Substratos }} \\
\hline & 128 células & 200 células & & \\
\hline Apical & $21,35 \mathrm{a} \mathrm{A}^{1}$ & $8,33 \mathrm{~b} \mathrm{~A}$ & Comercial & $5,36 \mathrm{~A}$ \\
\hline Mediano & 1,04 a B & 1,56 a A & $\mathrm{S} 1^{2}$ & $4,89 \mathrm{~A}$ \\
\hline Basal & 3,12 a B & $0,00 \mathrm{a} \mathrm{A}$ & $\mathrm{S} 2^{3}$ & $8,00 \mathrm{~A}$ \\
\hline CV (\%) & \multicolumn{2}{|c|}{9,40} & CV (\%) & 7,82 \\
\hline
\end{tabular}

Dados foram transformados pela equação $\sqrt{x+0,5} ;{ }^{1}$ Médias seguidas por letras minúsculas e distintas nas linhas e maiúsculas na coluna, diferem entre si pelos testes de Tukey a 0,05 de probabilidade. ${ }^{2} \mathrm{~S} 1=40 \%$ terra $+40 \%$ esterco bovino $+20 \%$ húmus; ${ }^{3} \mathrm{~S} 2=20 \%$ terra $+20 \%$ esterco bovino $+40 \%$ húmus $+20 \%$ vermiculita (data were transformed using the equation $\sqrt{x+0,5} ;{ }^{1}$ Means within the same row followed by distinct lowercase letters and means within the same column followed by distinct upper case letters are statistically different based on the Tukey test, $\mathrm{p}<0.05 .{ }^{2} \mathrm{~S} 1=40 \%$ soil $+40 \%$ cattle manure $+20 \%$ vermicompost; ${ }^{3} \mathrm{~S} 2=$ $20 \%$ soil $+20 \%$ cattle manure $+40 \%$ vermicompost $+20 \%$ vermiculite) .

Tabela 2. Brotação de rizoma (\%) de Dorstenia cayapia aos 68 dias após o plantio (rhizome budding (\%) of Dorstenia cayapia 68 days after planting). Uberlândia, UFU, 2007.

\begin{tabular}{|c|c|c|c|c|}
\hline \multirow{2}{*}{ Substratos } & \multicolumn{2}{|c|}{ Bandejas } & \multirow{2}{*}{\multicolumn{2}{|c|}{ Rizoma }} \\
\hline & 128 células & 200 células & & \\
\hline Comercial & $51,57 \mathrm{aA}^{1}$ & $6,81 \mathrm{bA}$ & Apical & $46,34 \mathrm{a}$ \\
\hline $\mathrm{S} 1^{2}$ & $17,77 \mathrm{aB}$ & $17,76 \mathrm{aA}$ & Mediano & $11,02 \mathrm{~b}$ \\
\hline $\mathrm{S} 2^{3}$ & $36,52 \mathrm{aAB}$ & $14,10 \mathrm{bA}$ & Basal & $14,88 \mathrm{~b}$ \\
\hline CV (\%) & \multicolumn{2}{|c|}{9,40} & CV (\%) & 14,38 \\
\hline
\end{tabular}

Dados foram transformados pela equação $\sqrt{x+0,5} ;{ }^{1}$ Médias seguidas por letras minúsculas e distintas nas linhas e maiúsculas na coluna, diferem entre si pelos testes de Tukey a 0,05 de probabilidade. ${ }^{2} \mathrm{~S} 1=40 \%$ terra $+40 \%$ esterco bovino $+20 \%$ húmus; ${ }^{3} \mathrm{~S} 2=20 \%$ terra $+20 \%$ esterco bovino $+40 \%$ húmus $+20 \%$ vermiculita $\left({ }^{1}\right.$ data were transformed using the equation $\sqrt{x+0,5} ;{ }^{1}$ Means within the same row followed by distinct lower case letter and means within the same column followed by distinct upper case letters are statistically different based on the Tukey test $\mathrm{p}<0.05 .{ }^{2} \mathrm{~S} 1=40 \%$ soil $+40 \%$ cattle manure $+20 \%$ humus; ${ }^{3} \mathrm{~S} 2=20 \%$ soil + $20 \%$ cattle manure $+40 \%$ humus $+20 \%$ vermiculite $]$.

Dorstenia cayapia, houve brotação de uma, e mais raramente, duas gemas em estacas contendo em média dez gemas (dados não apresentados). Almeida \& Pereira (2004) verificaram apenas uma gema brotada por seção de 1,5 a $2 \mathrm{~cm}$ de rizoma de Kohleria eriantha, contendo seis gemas. Nesse período analisado foi observada apenas a formação de cenantos masculinos, em alguns dos rizomas que brotaram. Apesar desta característica não fazer parte daquelas que foram analisadas, esta observação é um indicador de que a propagação desta dorstênia pode ser influenciada por fatores ambientais.

Ao final do experimento, observou-se alta taxa de enraizamento (aproximadamente $80 \%$ ) das estacas ao se avaliar a massa fresca e seca subterrânea, apesar de apenas $24 \%$ brotarem. Este fato deve ter ocorrido devido ao início do experimento ter sido realizado no outono, quando a maioria das dorstênias, por estresse hídrico, apresentam-se sem folhas. Leal \& Biondi (2007), trabalhando na propagação vegetativa por estaquia de Gloxinia sylvatica, com início do experimento no inverno, obtiveram conclusão semelhante. As estacas enraizadas, sem brotações, foram plantadas em vasos e a brotação ocorreu no início da primavera, confirmando Petry (1999) que menciona como a época mais adequada para o plantio de estacas, o início da primavera. Essas observações indicam que a brotação de Dorstenia cayapia pode ser controlada por fatores do ambiente, observado também por Almeida \& Pereira (2004), em brotação de rizomas de Kohleria eriantha.

Considerando a baixa porcentagem 
Tabela 3. Massa fresca e seca (g) de plantas provenientes de estacas de rizoma apicais de carapiá (Dorstenia cayapia) sob diferentes bandejas e substratos aos 68 dias, após plantio [wet and dry mass (g) of plants produced from cuttings of the apical rhizomes of carapiá (Dorstenia cayapia) in different trays and with different subtrates, about $72 \pm 2$ ( 22,3 months) after planting]. Uberlândia, UFU, 2007.

\begin{tabular}{|c|c|c|c|c|c|c|}
\hline \multirow{6}{*}{ Parte aérea } & \multirow{2}{*}{ Substratos } & \multicolumn{2}{|c|}{ Massa fresca } & \multicolumn{3}{|c|}{ Massa seca } \\
\hline & & 128 células & 200 células & 128 células & \multicolumn{2}{|c|}{200 células } \\
\hline & Comercial & $0,5757 \mathrm{aA}^{1}$ & $0,2085 \mathrm{bA}$ & $0,1188 \mathrm{aA}$ & \multicolumn{2}{|c|}{$0,0418 \mathrm{bA}$} \\
\hline & $\mathrm{S} 1^{2}$ & $0,5417 \mathrm{aA}$ & $0,2235 \mathrm{bA}$ & $0,1157 \mathrm{aA}$ & \multicolumn{2}{|c|}{$0,0490 \mathrm{bA}$} \\
\hline & $\mathrm{S} 2^{3}$ & $0,1637 \mathrm{aB}$ & $0,2605 \mathrm{aA}$ & $0,0375 \mathrm{aB}$ & \multicolumn{2}{|c|}{$0,0572 \mathrm{aA}$} \\
\hline & $\mathrm{CV}(\%)$ & \multicolumn{2}{|c|}{17,88} & \multicolumn{3}{|c|}{16,58} \\
\hline \multirow{5}{*}{ Parte subterrânea } & Substratos & Massa fresca & Massa seca & \multirow{2}{*}{ Bandejas } & \multirow{2}{*}{ Massa fresca } & \multirow{2}{*}{ Massa seca } \\
\hline & Comercial & $1,0095 \mathrm{AB}$ & $0,2704 \mathrm{~A}$ & & & \\
\hline & S1 & $1,1691 \mathrm{~A}$ & $0,2864 \mathrm{~A}$ & 128 células & $0,9900 \mathrm{a}$ & $0,2591 \mathrm{a}$ \\
\hline & $\mathrm{S} 2$ & $0,7691 \mathrm{~B}$ & $0,1821 \mathrm{~B}$ & 200 células & $0,9750 \mathrm{a}$ & $0,2335 \mathrm{a}$ \\
\hline & $\mathrm{CV}(\%)$ & 12,14 & 13,61 & $\mathrm{CV}(\%)$ & 12,14 & 13,61 \\
\hline
\end{tabular}

Todos os dados foram transformados pela equação $\sqrt{x+0,5} \cdot{ }^{1}$ Médias seguidas por letras minúsculas e distintas na linha e letras maiúsculas e distintas na coluna, diferem entre si pelos testes de Tukey a 0,05 de probabilidade. ${ }^{2} \mathrm{~S} 1=40 \%$ terra $+40 \%$ esterco bovino $+20 \%$ húmus; ${ }^{3} \mathrm{~S} 2=$ $20 \%$ terra $+20 \%$ esterco bovino $+40 \%$ húmus $+20 \%$ vermiculita (data were transformed using the equation $\sqrt{x+0,5} \cdot{ }^{1}$ Means within the same row followed by distinct lower case letters and means within the same column followed by distinct upper case letters are statistically different based on the Tukey test $\mathrm{p}<0.05 .{ }^{2} \mathrm{~S} 1=40 \%$ soil $+40 \%$ cattle manure $+20 \%$ humus; ${ }^{3} \mathrm{~S} 2=20 \%$ soil $+20 \%$ cattle manure $+40 \%$ humus $+20 \%$ vermiculite).

de brotação das estacas provenientes de rizomas mediano e basal, a massa fresca e seca foi avaliada somente nos rizomas apicais brotados até 68 dias após o plantio (Tabela 3). Para a parte aérea tiveram interação bandeja x substrato, sendo que os substratos Comercial e S1 obtiveram melhor desempenho, tanto na massa fresca quanto na massa seca, em bandeja de 128 células. No entanto, na parte subterrânea, que consistiu em rizoma + raiz, não houve interação bandeja x substrato, sendo que os melhores substratos, independente do tipo de bandeja, foram Comercial e S1.

A brotação da parte apical do rizoma foi superior às brotações das posições basal e mediana do rizoma. O uso da bandeja de 128 células foi melhor comparado com a bandeja de 200 células, nas brotações de rizoma. (Tabelas 1 e 2). Essa informação permite, a quem queira cultivar Dorstenia cayapia por estaquia de rizoma, o corte apenas da parte apical do rizoma, com $2 \mathrm{~cm}$, deixando o restante do rizoma no ambiente, fazendo assim um manejo sustentável. A exemplo do que acontece com inúmeras espécies de interesse medicinal e agronômico, a propagação vegetativa via estaquia de rizoma pode-se constituir num método eficiente para a multiplicação de Dorstenia cayapia.

O material vegetal extraído (384 plantas), após o término do experimento, contabilizando todas as plantas brotadas (não utilizadas para medir massa seca e as seções de rizoma de tamanho inferior e superior a $2 \mathrm{~cm}$ que foram plantadas em vasos), totalizando 1.213 plantas, foi replantado no ambiente de origem, em 9 de abril de 2008. Dessa forma foi devolvido à natureza o triplo do número de vegetais retirados da mesma.

\section{REFERÊNCIAS}

ALMEIDA JAS; PEREIRA MFD. 2004. Efeito da temperatura e do teor de unidade na iniciação e desenvolvimento do rizoma de Kohleria eriantha (Benth.) Hanst. (Gesneriaceae). Acta Botanica Brasilica 18: 863-869.

BOTSARIS AS; MACHADO PV. 1999. Memento terapêutico. Rio de Janeiro: Laboratório Flora
Medicinal. J. Monteiro da Silva. 91p.

CARAUTA JPP. 1978. Dorstenia L. (Moraceae) do Brasil e países limítrofes. Rodriguésia. 44: 53-223.

COSTA LCB; PINTO JEBP; BERTOLUCCI SKV. 2007. Comprimento da estaca e tipo de substrato na propagação vegetativa de atroveran. Ciência Rural. 37: 1157-1160.

KROGSTRUP P; FIND JI; GURSKOV DJ; KRISTENSEN MMH. 2005. Micropropagation of Socotran fig, Dorstenia gigas. Scrweinf. In vitro cellular \& developmental biology-plant 41: 81-86.

LEAL L; BIONDI D. 2007. Propagação vegetativa de Gloxinia sylvatica (H.B.\& K.) Wiehler. Revista Brasileira de Biociências 5: 300-302.

LOPES MS; STUMPF ERT; CARVALHO FIF. 2003. Efeito do substrato na reprodução assexuada de Limonium brasiliense (Boiss.) O. Kuntze. Revista Brasileira de Agrociência 9: 421-424.

MENDONÇA MP; LINS LV 2000. Lista vermelha das espécies ameaçadas de extinção da flora de Minas Gerais. Belo Horizonte: Fundação Biodiversitas - Fundação Zoo-Botânica de Belo Horizonte. 160p.

PETRY C. 1999. Plantas ornamentais: aspectos para produção. Passo Fundo: EDIUPF. 155p.

SETZER J. 1946. Contribuição para o estudo do clima do estado de São Paulo. São Paulo: Editoras Profissionais Salesianas. 239p. 